\title{
TEATRO E IMAGEN. EL PERFIL DE INSTAGRAM DE LA FURA DELS BAUS*
}

THEATRE AND IMAGE. LA FURA DELS BAUS ON INSTAGRAM

\author{
María José SÁnCHEZ Montes \\ Universidad de Granada \\ mariaj@ugr.es
}

\begin{abstract}
RESUMEN: A lo largo de estas páginas tratamos de seguir reflexionando sobre las posibilidades y ramificaciones de la idea de un teatro transmedia. En esta ocasión no pretendemos especular sobre el fenómeno como tal, ni desde el punto de vista teórico ni sobre sus intersecciones con lo teatral, sino desde la presencia en redes sociales y en concreto en Instagram de una compañía, La Fura dels Baus. Pensaremos también acerca de las implicaciones de esta presencia en relación con sus puestas en escena. En ese sentido nos preguntamos ¿qué construye La Fura a través de sus fotografías?, ¿qué nos invita a ver y en consecuencia a hacer?, y en última instancia, ¿cómo conforma nuestra mirada, es decir qué vemos y qué dejamos de ver?
\end{abstract}

PALABRAS CLAVE: Teatro, transmedia; La Fura dels Baus; Instagram

ABSTRACT: Throughout these pages we try to continue reflecting on the possibilities and ramifications of the idea of a transmedia theatre. On this occasion we are not going to speculate about the phenomenon as such, neither from the theoretical point of view nor about its intersections with the theatrical, but we are going to talk about the presence of La Fura dels Baus in social networks and specifically in Instagram. Furthermore, we will consider the implications of this presence in relation to their performances. Thus, several questions arise: what image of the company does La Fura build through its photographs? What invites us to see and consequently to do? and, ultimately, how does our view conform, that is, what we see and what we fail to see?

\footnotetext{
*Este artículo se integra dentro del trabajo realizado en el marco del proyecto I+D "Transmedialización y crowdsourcing en las narrativas de ficción y no ficción audiovisuales, periodísticas, dramáticas y literarias"
} 
KeYwords: Teathre, Transmedia, La Fura dels Baus, Instagram

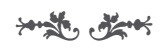

"El texto ha muerto (o se ha eclipsado para siempre): ¡viva la imagen y su presencia omnipotente!" (Abuín 2019: 85). Así comienza Anxo Abuín un texto muy reciente sobre los GIFs en el que hace referencia al triunfo del medio audiovisual sobre el universo literario. Ciertamente, "gracias a la explosión de formatos emergentes, redes sociales y plataformas [...] podcast, productos de Netflix, los memes de propaganda política, los canales de Instagram y YouTube" (86), vivimos en un momento en el que todo parece apuntar a que la imagen ha reemplazado la palabra. En el caso del teatro, que es el que nos ocupa aquí, no vamos a entrar a discutir cuestiones asociadas a esta sustitución porque nos llevaría a tener que considerar la relación entre el texto dramático y el espectáculo, asunto del que no son objeto estas líneas. No obstante, diremos que bajo nuestro punto de vista hablar de imágenes en el caso del teatro implica en última instancia situarse en el lugar de la escena, aunque las del espectáculo teatral sean efímeras e imposibles de fijar en soporte reproducible alguno sin que su especificidad se vea alterada.

Sin embargo, en esta ocasión quisiéramos adentrarnos en otro tipo de consideraciones. En concreto en el uso por parte de compañías teatrales de un tipo específico de imagen, la fotográfica, dentro de una estrategia más allá del propio espectáculo, pero vinculada a él y que consideramos transmedia. Se trata de cierta actividad asociada a la teatral, pero cuya vida tiene lugar en otras plataformas y formatos más allá de la escena, más allá del cuerpo del actor y del aquí y del ahora, del acontecimiento teatral, y que sigue teniendo la imagen como centro de su discurso. Así, a lo largo de estas líneas trataremos de continuar reflexionando sobre las posibilidades y ramificaciones de la idea de un teatro transmedia, aunque no sobre el fenómeno como tal desde el punto de vista teórico o de sus implicaciones en relación con el concepto de teatro. Nos vamos a centrar, por el contrario, en un aspecto muy concreto, la presencia en la red social Instagram de una compañía, La Fura dels Baus, y de algunas ramificaciones de esta presencia en la red en general y en relación con sus puestas en escena en particular.

\section{ANTECEDENTES}

Durante los últimos años y en el marco del proyecto liderado por el profesor Sánchez-Mesa Martínez en la Universidad de Granada, Narrativas transmediales: nuevos modos de ficción audiovisual, comunicación periodística y performance en la era digital, nos hemos venido preguntando acerca de la existencia de algo que podríamos denominar teatro transmedia. A lo largo de varios trabajos (Grande Rosales y Sánchez Montes 2016; Sánchez Montes 2019) e intervenciones públicas 
hemos tratado de pensar en el significado del espectáculo transmedia en relación con lo que supone para el concepto de teatro y con el posible abandono del espacio habitual de la representación. También hemos llamado la atención acerca de sus consecuencias vinculadas a una determinada idea de lo teatral sostenida sobre los pilares del cuerpo del actor, del encuentro, del aquí y del ahora.

En la última década, y me refiero exclusivamente al ámbito teatral, se han venido desarrollando estrategias que podemos denominar transmedia. Estas estrategias tienen como objetivo o bien poner a disposición del espectador material producido en torno al espectáculo (cuadernos de dramaturgia, partituras corporales, fotografías de ensayo, videos de los ensayos o el montaje, diseño de vestuario o escenografía, planta de luces, etc), o bien dar acceso al proceso de construcción del espectáculo como parte de una estrategia de marketing. En alguna otra ocasión incluso han servido como modo de canalización de un deseo de incorporar al espectador, aunque siempre de manera controlada y con el objetivo de mantener vivo el espectáculo más allá de su carácter efímero.

Por lo que respecta al vínculo con el teatro digital, la presencia de lo teatral en redes, de forma transmedial, no tiene por qué condicionar al espectáculo en ese sentido. Para ello partimos de la definición de que el teatro digital,

\footnotetext{
... sería aquel en el que espectador y actores comparten el mismo espacio en tiempo real, pero la acción dramática está mediada por las nuevas tecnologías y el software forma parte de la dramaturgia del espectáculo, produciéndose una interacción entre el espacio digital y el espacio real. (Grande Rosales y Sánchez Montes 2016: 3)
}

En el caso de las estrategias transmedia ni actores ni espectadores tienen por qué compartir el mismo espacio en tiempo real, ni la dramaturgia se ve en la mayoría de los casos alterada por la presencia en redes de los espectáculos. El uso de redes sociales por parte de compañías teatrales nos confronta con un acontecer respecto del espectáculo que se nos antoja más vinculado a la idea de rizoma descrito por Deleuze y Guattari. Los distintos materiales que se ponen a nuestra disposición, fotografías, textos o vídeos, nos permiten acceder a la puesta en escena desde otros extremos generalmente independientes de la misma, hacerlo en momentos distintos a los del encuentro con los espectadores, conectar algunos de esos materiales, ponerlos en relación sin necesidad de pasar por el propio espectáculo, observar un mapa diverso y expandido del mismo espectáculo teatral y en última instancia interpretar "una obra que de hecho no se ofrece sino a la experimentación" (Deleuze y Guatari 1978: 11).

A lo largo de nuestra indagación durante los últimos años hemos explorado algunas prácticas teatrales contemporáneas y podemos concluir que en la mayoría de los casos de teatro transmedia analizados todavía carece de todo el desarrollo de su potencial. Ciertas puestas en escena o bien planteaban directamente lo transmedia como estrategia captadora de espectadores, o bien como intento de renovación de algunos aspectos de la puesta en escena. Sin embargo, hemos llegado a considerar algún caso como el de la compañía de danza Rosas y su espectáculo Rosas Danst Rosas que no se planteaba lo transmedia como tal 
pero se adentraban en el territorio a través de la apertura de un canal en YouTube. ${ }^{1}$ Esta actividad paralela pero íntimamente relacionada con el espectáculo en definitiva lo expande, lo perpetúa a través de la red y establece una suerte de diálogo entre actrices y espectadores convertidos a través del propio canal en ejecutantes de la emblemática coreografía.

Por otro lado, en el capítulo aparecido recientemente en el monográfico publicado en la editorial Gedisa (Sánchez Montes 2019) hemos reflexionado también sobre el hecho de que el nombrar lo transmedia en teatro tanto como estrategia de venta o como forma de atraer espectadores puede que no suponga un cambio en el modo de hacer, es decir, que no implique ni una variación sustancial en la percepción del mismo ni en la construcción del espectáculo, y generalmente por todo ello el concepto de teatro permanece intacto.

En ese sentido, y si partimos entonces del cuerpo como elemento inequívoco y casi imprescindible de la puesta en escena, o como diría José Antonio Sánchez, "lo que le sobra al discurso de la realidad virtual y que el teatro una vez más reivindica como ineliminable y propio" (Sánchez Martínez, 2007: 275), la actividad asociada a lo teatral en las redes sociales no puede ser considerada estrictamente teatro. Si al prescindir del cuerpo físico frente a la virtualidad de las imágenes que reproducen su apariencia abandonamos la escena habremos de preguntarnos si abandonamos también una cierta concepción de teatro. Siendo así, y como conclusión provisional, el teatro transmedia no existiría o al menos no hasta el momento según las tecnologías disponibles y las prácticas escénicas actuales.

No obstante, como dijimos al inicio de estas páginas, nos interesa en esta ocasión otro tipo de corporalidad, aquella a la que se refiere Óscar Cornago cuando afirma que la sociedad de los medios es "una sociedad de cuerpos sin cuerpo, cuerpos convertidos en imagen que viajan a la velocidad de Internet" (2008: 51). Son esos cuerpos relacionados con la imagen los que nos interesan en esta primera aproximación a la presencia en redes de compañías teatrales y al vínculo con espectáculos que no necesariamente tienen que ser ni multimedia, ni virtuales, ni estar vinculados con las tecnologías digitales. Nos preguntaremos en el caso concreto de La Fura dels Baus qué uso hacen de las imágenes, cuál es su vínculo con sus espectáculos teatrales, qué se moviliza, qué se propone al espectador y qué dice o cuenta la compañía de sí misma a través del mural de imágenes y cuerpos digitales desplegados en internet.

La Fura dels Baus comienza su trayectoria a finales de los años 70 pero no será hasta el año 1983 cuando den el salto definitivo al panorama nacional, y rápidamente al internacional, de la mano de su espectáculo Accions. Junto con los dos siguientes, Suz o suz y Tier Mon, Accions se centraban en lo físico, en el encuentro entre actores y espectadores, y todavía estaban muy lejos de constituir nada cercano al teatro multimedia o digital. No obstante, La Fura comienza a

\footnotetext{
1 La apertura del canal por parte de la compañía tuvo más que ver con razones vinculadas al propio éxito del espectáculo, a la denuncia a Beyoncé por uso fraudulento de esa y de otras coreografías de la compañía y a la celebración de los 30 años del estreno. Para acceder a esos videos y a toda la información sobre el proyecto: https://www.rosasdanstrosas.be/en-home/
} 
experimentar a ese respecto a partir de su espectáculo Noun estrenado en 1990. Este espectáculo incorporaba ya elementos que lo hacían un espectáculo multimedia, e inauguraba un periodo de casi tres décadas de incursiones variadas en el mundo del teatro digital. Ahora bien, como ya hemos señalado, no es nuestro objeto en este momento ni hablar de teatro digital ni de lo digital en los espectáculos de La Fura. Su historia respecto a la incorporación a sus espectáculos de las tecnologías de su tiempo es compleja y diversa, ${ }^{2}$ pero por lo que respecta a su llegada al universo transmedia nos parece que no tiene tanto que ver con lo experimental para la escena sino más bien con una estrategia de mercado.

\section{Plataformas y Redes: Instagram}

Domingo Sánchez-Mesa señalaba que,

... desde luego es evidente que ni Internet ni el ciberespacio han acabado con grandes tecnologías culturales y modos de comunicación del pasado (ni las culturas orales, escritas, ni los medios de masas como la televisión o el cine desaparecen con la cibercultura). Eso sí, han modificado sus modos de creación, producción, distribución y consumo. (Sánchez-Mesa 2015: 90).

Con Sánchez-Mesa pensamos que Internet y el ciberespacio no solo modifican los modos de creación, producción, distribución y consumo, sino que este espacio que es artificial o virtual también lo es físico, "porque depende del entramado material de sistemas y redes que le sirven de sustento e interactúa y se proyecta en el mundo no virtual" al que puede alterar o altera y condicionar además su uso (Robles 2016: 17). En ese sentido nos preguntamos qué construye La Fura a través de sus fotografías, qué nos invita a ver y en consecuencia a hacer y en última instancia cómo conforma nuestra mirada, es decir qué vemos y qué dejamos de ver.

Facebook, Instragram, YouTube son algunas de las plataformas que se nos ofrecen para habitar ese espacio artificial, respondiendo a esta época y al momento presente. Como dice Abuín, se trata además de redes obsesivamente democratizadas y entregadas a lo amateur (2009: 86). Esa realidad además permite que encontremos usos muy diversos, aunque mayoritariamente parecen estar siendo utilizadas como modo de vender una marca ya sea personal o corporativa, dar imagen a una idea o a una visión, o como estrategia de marketing.

La Fura dels Baus cuenta con perfil en algunas de las redes sociales más importantes, Facebook, Twitter, Instagram e incluso tiene un canal de YouTube. Excepto el canal de YouTube, que merecería consideración aparte, las otras tres redes prácticamente albergan y difunden la misma información. Lo único que las distingue no proviene en este caso del emisor sino del formato impuesto por la propia red, es decir, de la manera en que se despliegan ante la audiencia la palabra y la imagen. En esta ocasión nos vamos a detener en Instagram porque,

\footnotetext{
2 Para consultar algunas menciones en este sentido ver Abuín, (2008), Cendrós, (1997), León Rol-
} dán (2004) y Sánchez Montes, (2013). 
aunque la información que se ofrece y el acceso al espectáculo es análogo a lo que se ofrece en las otras dos, lo que se construye visualmente difiere por su propia configuración.

Instagram nació en octubre de 2010 como una red que quería tener la imagen como motivo y elemento central. Tanto Twitter como Facebook permitían subir fotografías, pero era y sigue siendo el texto el que de alguna manera protagoniza la comunicación en ambas. Es destacable que, frente a las otras dos, Instagram sea la red que más crece a diario,

... en junio de 2018 la red contaba con 1.000 millones de usuarios activos mensuales, de los que la mitad usan la aplicación diariamente. Su ritmo de crecimiento ha sido espectacular para tan corta vida: cada día se registran más de 730.000 nuevos usuarios. Es una red donde se comparten diariamente más de 80 millones de fotos y vídeos y con una alta presencia empresarial. (CantónCorrea y Alberich-Pascual 2019: 2)

La imagen proyectada a través de esta red social contribuye a la idea de que esta participa de un "lenguaje universal y de una forma natural y espontánea de relacionarnos con los demás" (Cantón-Correa y Alberich-Pascual 2019: 3). Del mismo modo que Cantón y Alberich reflexionan sobre la construcción social de la cultura visual respecto a la ciudad de Granada, nos gustaría pensar cómo se construye la imagen visual de una compañía escénica que precisamente sustenta su ser como tal en un teatro que tiene como centro la creación y proyección de imágenes. En ese sentido seguimos la senda que abría Domingo SánchezMesa al pensar en las imágenes de las cubiertas de los libros de Vila-Matas cuando se preguntaba,

¿Qué quiere decirnos el autor de El mal de Montano con las fotografías que forman parte del aparato paratextual de sus libros? ¿Cabe pensar que ese tipo de imágenes, tan particulares y evidentemente vinculadas, en una suerte de serie, no están implicadas en la red de significados que va tejiendo la obra de EVM? (Sánchez-Mesa 2015: 766)

Así, trataremos de preguntarnos qué nos dicen todas estas imágenes que se agolpan en nuestra retina y que conforman un mural de color, donde el cuerpo es el protagonista porque es el elemento que se nos ofrece con más frecuencia ante nuestros ojos a través de la pantalla líquida.

\section{LA FuRA DELS BAUS EN LAS REDES SOCIALES: INSTAGRAM}

La Fura dels Baus inaugura su página de Instagram el 27 de junio de 2013 con motivo del espectáculo Afrodita o el juicio de Paris, anunciado en el pie de la foto (https://www.instagram.com/p/bEOjGeM7ia/) de la siguiente manera,

Afrodita y el juicio de Paris es el primer show viral de La Fura. Sigue todos los detalles del espectáculo que inaugurará Temudas fest 2013 a través de las principales redes sociales con el hashtag \#AfroditaCanarias! \#viralshow \#temudasfest \#grancanaria \#laspalmasdegrancanaria 
A 22 de agosto de 2019, es decir casi 6 años más tarde, la red cuenta con 490 publicaciones y 10.000 seguidores. Observando estos datos, la frecuencia media de publicación de fotos ha sido más o menos cada seis o siete días, y como dato significativo señalaremos, no sin cierta sorpresa, que en ni una sola foto aparecen los créditos de la misma.

Afrodita y el juicio de Paris se estrenó el 5 de julio de 2013. Mientras que desde el 27 de junio de 2013 y hasta el estreno se subieron fotografías del proceso de montaje y algunos ensayos, durante los dos días siguientes y hasta el 7 de julio de 2013 las fotos tuvieron que ver con el espectáculo en su representación. En total se subieron a la cuenta de Instagram sesenta y ocho fotos, de las cuales un poco menos de la mitad correspondían a las dos funciones que hicieron del espectáculo. Así, La Fura no solo retransmitió información del proceso de construcción del espectáculo on site, sino también del propio espectáculo en su celebración. Es importante destacar que la foto número diecinueve (https://www. instagram.com/p/bQn5cRM7/6/) es una fotografía de una imagen que formaría parte de la puesta en escena y que llamarían red humana, ${ }^{3}$ motivo recurrente en el universo espectacular y escénico de La Fura pero sobre todo en su perfil de Instagram.

La red humana, formada por cuarenta y dos participantes suspendidos en el aire, Se utiliza por primera vez en una dramaturgia espectacular en el año 2005. En su página web ${ }^{4}$ se refieren a este elemento como

\begin{abstract}
... un elemento escenográfico capaz de generar coreografías aéreas en las que intervienen un gran número de participantes. La Red tiene como base una gran viga metálica suspendida de una grúa. Es capaz de formar diferentes figuras mediante pistones hidráulicos. La espectacularidad de este elemento se define a partir de la suma de sus posibilidades de transformación y de las evoluciones de los actores que cuelgan de él. Así, desde el punto de vista del espectador, la Red propone un impacto completo, es el resultado de la mecánica y de la parte gestual, propone una metáfora muy elaborada que tiene que ver con la reunión, con el complementario, con la suma de esfuerzos, con todas las estructuras humanas que representamos como red y conexión (genoma, tejido nervioso, unión, participación, etc.).
\end{abstract}

Curiosamente, durante el año 2013 el otro acontecimiento que merece lugar en la red social es la participación del grupo a finales de julio en el congreso organizado por la IFTR (International Federation of Theatre Research) en la ciudad de Barcelona, es decir, no tiene que ver con ninguna representación ni con ningún espectáculo o proceso de creación (https://www.instagram.com/p/cKB-G_s7o1/). Hasta prácticamente un año después no volverían a activar las publicaciones de la cuenta y lo harán en concreto el 25 de abril de 2014 para anunciar las representaciones de Carmina Burana que tendrían lugar en Pamplona los días 2 y 3 de

\footnotetext{
${ }^{3}$ La cursiva es nuestra.

4 https://www.lafura.com/obras/red-humana/
} 
mayo (https://www.instagram.com/p/nOAgtrs7oe/). Unos días más tarde, el 29 de abril, anunciarían con las fotografías correspondientes M.U.R.S. (https://www. instagram.com/p/nX-v0Es7ue/), denominado por ellos como el primer smart show de La Fura. El espectáculo que partía de la idea de muro, y sobre todo de los muros no físicos que las nuevas tecnologías construyen a nuestro alrededor, iba a tener lugar en el castillo de Montjuïc. Como hemos dicho, se anunciaba como smart show y utilizaba el teléfono móvil y una aplicación que los espectadores habían de descargar y que servía para confrontar a los asistentes con la idea de control en relación con la información o desinformación impuesta a través de los medios digitales.

Hasta ese momento, y a lo largo de casi el primer año de actividad en Instagram, su presencia no solo tuvo tímidamente que ver con la posibilidad de dar acceso desde la fotografía a ciertos aspectos de sus espectáculos, sino que sirvió como plataforma para canalizar una preocupación que llevaba habitando algunos de ellos desde hacía veinte años con MTM. Este espectáculo estrenado en 1994 se construía a partir de la mirada hacia la manipulación ejercida por los medios de comunicación audiovisual, y veinte años más tarde M.U.R.S. seguía confrontando a los espectadores con el mismo asunto.

El 20 de noviembre de 2014 aparece por primera vez Turn On the Lights cuya fotografía en Instagram sirve para anunciar un espectáculo cuya intención es volver a los orígenes o a lo que ellos mismos denominan "lenguaje furero". El espectáculo parecía querer establecer vínculos también con los inicios y el camino recorrido a través de la experimentación con los medios digitales, también mediante los macroespectáculos y la ópera, y utilizaban la mencionada red humana como uno de los principales motivos visuales del espectáculo: ${ }^{5}$

Turn on the Lights es un acto eminentemente visual y poético que combina imágenes cinéticas y sonidos vibrantes. Representará el proceso de búsqueda interior en el ser humano, la sensibilización sobre el proceso que, día tras día, ayuda al ser humano a concebir el mundo con una nueva y sorprendente visión.

Será un año más tarde cuando por fin recuerden sus orígenes y suban a la red social una foto de Accions, su primer espectáculo. Concretamente el 17 de diciembre de 2015 aparece esa imagen (https://www.instagram.com/p/_ZyW4os7hf/) con el siguiente pie de foto:

Miki Espuma: "Accions era el revulsivo necesario, la excusa para potenciar definitivamente la energía colectiva, para desatar la intuición. Es, por encima de otras consideraciones, la consecuencia de la búsqueda de una estética propia".

Accions, como ya he señalado, era un espectáculo sobre todo físico, fundamentado en el encuentro entre ejecutantes y espectadores, para nada próximo ni al teatro multimedia ni a la reflexión sobre el mundo digital, y desde luego en las antípodas de cualquier estrategia transmedia. A partir de la publicación de esta

${ }^{5}$ https://www.lafura.com/obras/turn-lights/ (23 de agosto de 2019). 
foto apareceran más imágenes de los espectáculos primeros, en concreto de los cinco inciales, incluida su obra $A D N$ que se anuncia con una foto el 30 de junio 2016 (https://www.instagram.com/p/BHSgCUBgmq0/), que combinaba acciones de la primera trilogía Accions, Suz/O/Suz y Tier Mon. En ellos se exploraba entre otras cosas la frontera tradicional entre público y actor. Curiosamente este espectáculo reivindicaba esa cercanía de sus primeros tiempos como lugar necesario de indagación en la era de la cibercultura y la virtualización.

\section{CONCLUSIONES}

En general, podemos decir que el perfil de Instagram de La Fura dels Baus alterna fotos de actos públicos, como ruedas de prensa, con fotografías anunciando los espectáculos, pero no hay imágenes del proceso de construcción de la puesta en escena, ni tampoco de los ensayos previos a los estrenos. Su expansión narrativa, o la estrategia transmedial, podemos concluir que hasta la fecha tiene que ver sobre todo con la estrategia de comunicación de la compañía como empresa y por tanto con la publicidad de sus espectáculos. Así, estos permanecen en ese sentido intactos porque la actividad en las redes y en Instagram no tiene retorno hacia ellos. Lo que ocurre en Instagram no tiene impacto alguno en ninguno de los aspectos de sus espectáculos, entendemos que por el reducido número de personas que los siguen en relación con los espectadores a los que acaban llegando sus puestas en escena. Podríamos decir que La Fura no parece tener una estrategia clara sobre qué se puede hacer o quieren hacer en concreto en Instagram. No obstante, el que no tenga definidas claramente lo que quieren o pueden contar o decir sobre sus espectáculos, desde el punto de vista también de la estética o de la imagen que construyen, no significa que no digan nada.

El perfil de Instagram comunica, pero lo hace afirmando en una serie de direcciones que parecen iniciar que no están cuidadas necesariamente por la empresa. En el mural de fotografías que podemos ver al entrar en su perfil se suceden todo tipo de angulaciones, suelen predominar los rojos y azules, casi siempre aparece la imagen de un cuerpo, pero no parece haber una estética uniforme ni en el tipo de fotos, ni en los objetos o en la paleta de color. Sin embargo, sí es destacable un hecho y es que hay un motivo, aunque no siempre fotografiado desde el mismo ángulo ni se trata siempre de la misma fotografía, que es utilizado recurrentemente a lo largo de estos casi seis años de presencia en Instagram. La red humana es la imagen que más aparece en el perfil y lo hace de manera consistente, la única que se repite cada tanto y la más publicada con diferencia. Viene así a convertirse en una seña de identidad de la compañía, casi como si de una marca de agua se tratase, una suerte de motivo recurrente que nos hace volver a un mismo lugar, ya que algo de lo que este grupo quiere decirnos sobre sí mismos se encuentra contenido y se proyecta en ella.

Si al final de nuestra aportación sobre lo transmedia en el ámbito teatral como moda o como modo (Sánchez Montes, 2019: 229) seguíamos instalados en las preguntas y nos planteábamos qué invita a hacer un espectáculo transmedia, 
ahora nos planteamos cómo nos convoca la estrategia transmedia. De ahí nos gustaría enlazar con la idea de que en última instancia este tipo de maniobra exigen un modo de pensar en el espectador. Lo transmedia reconoce la presencia del receptor que de algún modo se incorpora en este caso al espectáculo con solo posar su mirada en una serie de fotos. La mirada se llena de imágenes que "cuentan" algo sobre el grupo, su estética, sus espectáculos, su color, sus cuerpos.

En ese sentido, pensar en el uso de las redes sociales en relación con la actividad teatral de ciertos grupos, como ya hemos venido diciendo, nos constituye como espectadores de manera diferente. Esto es así no solo porque desde el punto de vista receptivo las tecnologías digitales enfatizan la recepción individual, en un último paso hacia el aislamiento comunicativo, hacia una especie de onanismo espectacular (Sánchez 2007), sino porque la entrada al espectáculo a través de la "puerta" de las redes sociales viene condicionada por una primera recepción del mismo que tiene que ver con una experiencia mediada por una pantalla.

El espectáculo transmedia, como venimos diciendo, implica al espectador y lo emplaza a lugares no físicos en los que recoge información o accede a partes del espectáculo que le permitirán tener una experiencia en principio más plena del mismo. Sin embargo, aunque las estrategias transmedia presuponen un espectador, este no está únicamente convidado al acto teatral, porque a través de los distintos perfiles y canales se acumula otro tipo de información a la que se puede acceder con posterioridad. No obstante, la que circula próxima pero separada del acto teatral genera un tipo de recepción desfasada del momento de producción. Y no solo eso, la recepción puede producirse en el ámbito doméstico, pero también en cualquier otro tipo de situación social o de espacio incluso, en virtud de la posibilidad de acceso a estos materiales a través de los smart phones, con las interferencias que puede llevar aparejadas.

Así, y volviendo a nuestro objeto, La Fura nos invita a pensarnos como espectadores de sus espectáculos con acceso a través de esa mirada potencialmente interferida, y claramente de modo más o menos intencionado. Y más allá de la estrategia publicitaria de sus espectáculos cuentan algo de sí, comunican a través de su perfil de imágenes, fragmentan incluso una "narración" principal y la colocan en distintos lugares, nos ofrecen distintas puertas de acceso a su propuesta que en definitiva, y a la espera de continuar reflexionando sobre ello, navega desde el cuerpo físico a la imagen del cuerpo y nos devuelve precisamente a través de una red humana al origen, al suyo y en última instancia al del teatro, a aquello de lo que por lo que a él respecta todavía no hemos podido prescindir: al cuerpo real.

\section{OBRAS CITADAS}

Abuín González, Anxo (2008): "Teatro y nuevas tecnologías: conceptos básicos", Signa: revista de la Asociación Española de Semiótica, n. ${ }^{\circ}$ 17, pp. 29-56. 
- (2019): "Bucles no tan extraños: espectografías shakesperianas en el universo GIF". En Domingo Sánchez-Mesa Martínez (ed.): Narrativas transmediales. La metamorfosis del relato en los nuevos medios digitales. Barcelona, Gedisa, pp. 85-106.

Cantón-Correa, Francisco-Javier; Alberich-Pascual, Jordi (2019): "Construcción social de la imagen de una ciudad a través de Instagram: el caso de Granada", El profesional de la información, v. 28, n. ${ }^{\circ} 1$.

Cendros, Teresa (1997): "La Fura dels Baus crea un laboratorio de teatro digital", El País, 17 de julio.

Cornago Bernal, Oscar (2008): Éticas del cuerpo. Madrid, Fundamentos.

Deleuze, G.; Guattari, F. (1978): Kafka. Por una literatura menor. México, Ediciones Era.

Grande Rosales, María Ángeles; Sánchez Montes, María José. (2016): "Posibilidades de un teatro transmedia". En Domingo Sánchez-Mesa, Jordi Alberich-Pascual, Nieves Rosendo (coords.): "Narrativas transmediales", Artnodes, n. ${ }^{\circ}$ 18, pp. 1-9.

León Roldán, Miguel Ángel (2004): F@usto 3.0: El teatro digital de La Fura dels Baus en Arte y nuevas tecnologías: $X$ Congreso de la Asociación Española de Semiótica. Logroño, Universidad de La Rioja y Fundación San Millán de la Cogolla, pp. 668-680.

Robles, Margarita (2016): “El ciberespacio: Presupuestos para su ordenación jurídico-internacional", Revista chilena de derecho y ciencia política, vol. 7 n. ${ }^{\circ}$ 1, pp 11-56.

Sánchez Martínez, José Antonio (2007): "De las dramaturgias de la imagen a las dramaturgias de la imaginación", Estudis escènics: quaderns de L'Institut del Teatro de la Diputación de Barcelona, n. ${ }^{\circ} 32$, pp. 270-280.

Sánchez-Mesa Martínez, Domingo (2015): "Los estudios sobre la cibercultura y los new media. Extendiendo el campo de la literatura comparada", Caracteres. Estudios culturales y críticos de la esfera digital, vol. 4 n. ${ }^{\circ} 2$.

_ (ed.) (2019). Narrativas transmediales. La metamorfosis del relato en los nuevos medios digitales. Barcelona, Gedisa.

Sánchez Montes, María José (2013). "Realidades virtuales: Johannes Birringer", Teatro e Internet en la primera década del siglo xxI. Madrid, Verbum, pp. 533-545

- (2019). "Teatro transmedia ¿modo o moda?". En Domingo Sánchez-Mesa Martínez (ed.): Narrativas transmediales. La metamorfosis del relato en los nuevos medios digitales. Barcelona, Gedisa. 